\title{
Influence of Interior Color and Material Matching Design of the Yacht to the Consumer Psychology
}

\author{
Zhuo Jin \\ Marine Convergence Design \\ Pukyong National University \\ Bozhou University \\ Bozhou, China 236800
}

\author{
Chul Soo Kim \\ Departement of Industrial Design \\ Pukyong National University \\ Busan, Korea
}

\begin{abstract}
With the development and improvement of the global economy, people's demand for the quality of life is not only confined to food and clothing, but pursue more diversified life and entertainment. The yacht are popular for consumers in the coastal cities. The design and color of yacht have an important impact on people's consumption psychology, the interior color design of the yacht can reflect the aesthetic feeling and level of the yacht, at the same time, express the personality of buyers, explore the appliance of interior color and material matching of the yacht as well as explore influence of color and material to consumers, thus stimulating the buying inclination of consumers and letting users of the yacht get the enjoyment of physical and mental pleasure. Methods: Starting from the design of interior color for yacht, the paint color is explored, material quality is reasonably collocated, purchase intention of consumers is analyzed from the visual stimulation, color emotion and consumer psychology; Conclusion: the design of the yacht should conforms to modern people's aesthetic temperament and interest through ways of design to cause buying inclination and promote marketing.
\end{abstract}

Keywords-Interior of the yacht; color design; material matching; consumer psychology; marketing strategies

\section{ANALYSIS OF YACHT INTERIOR DESIGN}

As a popular water leisure equipment, yachts satisfy most people's functional requirements such as navigation, recreation, sightseeing and business activities. In order to meet the practical needs of consumers for yacht, designers must have a full range of three-dimensional design of the yacht's interior. The yacht's interior design includes the work room, public storage room and living room design. The more detailed design also includes the internal structure of the yacht layout, color matching, space use, functional planning, dirt discharge devices, and so on. Yacht interior design should care about the soft sense of the environment and the sense of harmony of the colors, as well as the choice of decorations and decoration materials.

1. About the author: Jin Zhuo, male, (1983.2-) in Shenyang Liaoning associate professor at Bozhou University, a doctoral student learning in Pukyong National University, majored in: vision design marketing and brand planning

2. About the author: Kim Chul Soo, (1960.7-) male, born in Busan Korea, professor at Pukyong National University, majored in: Departement of Industrial Design

\section{THE RELATIONSHIP BETWEEN COLOR EMOTION AND CONSUMER PSYCHOLOGY}

Consumer psychology broadly refers to the psychological reactions of the consumers in the process of purchasing desired goods. In general, it includes people contact goods, next pay attention to it, then through the exploration and comparison, they fall in love with it, at the same time, the purchase desire arise. If the purchase conditions and money allow, they will make the corresponding consumption decision. After a period of probation, they have a real experience and consider whether to buy again. In such consumer psychological activities, many factors will have an impact on consumers' mentality. Color is one of the important factors that mostly are determined by the collocation with distinctive characteristics and the applicability. But the most cause for concern is whether it can bring people comfortable psychological sensation and perception of enjoyment. Therefore, a good color design will convey a different emotion, and it is the first powerful element to attract consumers.

Consumers will have a psychology of pursuing value. The love feeling of a product mostly due to the appearance, packaging design and the practical value. Like the color design mentioned above, color is the first factor to attract consumer attention, not only because of the good feelings makes people at ease, but also because of the reasonable color design could enable such feelings to maintain for a long time. In other words, the term of using is extended by this love feeling, namely the initiative of purchasing products is mobilized and the value of products is developed by consumers in the process of using. Therefore, the expression of color emotion has become an important link in the realization of the value of commodities.

Considering the impact of color emotion on consumer psychology from objective perspective, the concept of color emotion is very abstract, but fortunately consumers can understand through actual life and experience. As people express their emotion through actions, speech and face, the colors convey a special emotion through tone, transparency and collocation. Color owes such an ability to transmit emotion which the receiver subjectively feel. The design of color needs to be based on people's physiology and emotion 
for the perfect effect of color collocation to make people have the beauty feelings.

\section{The SPACE Color and Material Collocation USED FOR YACHT INTERIOR DESIGN}

\section{A. The Space Color and Material Collocation Used for Yacht Work Room}

The working cabin in the yacht is generally referred to the engine room and the cockpit, which is a very important place to ensure the safety and proper operation of the yacht. The cockpit is the headquarters of the whole yacht, like the brain in the human body, that controls all the human behavior. Designers should be guided by the theoretical foundations of engineering. In color design, the designer should cater to the needs of the driver, choosing the color can greatly reduce the fatigue of the driver. So for the cab roof color and material selection, the most common used color is warm tone that can coordinate with the surface of the wall and avoid unexpected sense. Easily reflected light material is not suitable for the ground. We can choose wood materials or other soft colors to avoid stimulation of the driver. In the room, we can arrange some green displayed as the map shown. The green potted plant or some blue jewelry can alleviate the driver's fatigue. However, remember that ensure the driver's vision is not affected. The cabin room where placed a heavy machine. These devices are often placed in the environment of high temperature or poor lighting, so we should select the color that can increase the brightness for working smoothly. At the same time, in choosing decoration materials, because the poor lighting may cause indoor humidity, please do not to choose wooden materials in case of corruption or other problems. Therefore, the cabin roof use white. As for wall color, it is best to use cool tone. This can make people's mind relaxed and peaceful while working, so as to improve the enthusiasm of the crew.

\section{B. The Space Color and Material Collocation Used for Yacht Public Room}

Yachts are divided into different categories according to their functions. The leisure hall, conference room and the dining hall are all public cabins in the yacht. Leisure hall is the main place for people to relax and enjoy, so the color chosen for here should be warm tone, such as orange, red, pink and so on, to bring a warm and lively feelings for people. In the leisure and entertainment hall, the interior layout can't be too rigid. When placing items we can choose leather seat to let people feel soft and safe. The choice of lighting is also important. Gorgeous lights could stimulate the soul of the real self, so that people can freely vent and release pressure. So you can choose to adjust the brightness of the light to let people produce a pleasant and completely relaxed feeling. At the same time, we should select the corresponding bright color decorations to make indoor looks harmony. But it could not be too complex, in case the whole color collocation is inconsistent. Correspondingly, the conference hall requires rational color and too comfortable and soft environment may make people feel tired and decadent, so the color matching in the conference hall can't be too flowery. The metal materials could make the nerve highly concentrated. Appropriate placement of metal items can improve people's work efficiency and nervous tension to maintain a serious and rigorous work attitude. Dining room should use warm colors. Scientific research shows that warm colors are conducive to increase people's appetite, so that it can produce a relaxed environment when people at the meal. Dining hall can choose wooden decorations matched with light, white or warm orange color to show a clean and sanitary dining environment and bring people a sense of security and trust. Public rooms are place for people to work together, and its environmental sanitation must be guaranteed. Therefore, in the choice of interior decoration, you must choose bright material that easy to clean.

\section{The Space Color and Material Collocation Used for Yacht Living Room}

Living quarters are where people rest and live. In accordance with the "people-oriented" principle, we must consider people's needs for life to design a quiet, elegant, soft indoor environment. Designers should take into account people's living experience, habits, and use color to comfort people's psychology to make people find a sense of belonging. Therefore, the decoration of the wall is best to choose a bright light tone that could produce a particularly unique and warm environment. Such as light green, light yellow, beige and so on. For the choice of carpet colors, we can use dark or soft colors and prevent using reflective wooden floors or other materials. The sofas, seats, curtains, and other ornaments of the living room should be in harmony with the tones. Do not use too strong color that may give people a visual impact. We should try our best to create a gentle, coordinated, quiet place of rest.

\section{THE IMPACT OF COLOR DESIGN IN YACHT ON CONSUMER PURCHASING DESIRE}

\section{A. The Impact of Color Design on Consumer Purchasing Desire}

As a commodity in the seller and consumer trading relations, in order to stimulate people's desire to buy, the design of the color must be combined with the feelings of the people. So it requires designers to make a scientific analysis of color choice and collocation, and integrate them with consumers' psychological feelings and experiences. Some famous art scholars abroad have made the color rational and abstract, and then transformed the color geometry to master the emotion and the experience of the color. In the modern color design, there exist a dangerous hidden defect. The most common phenomenon is the self-centered color processing. Designers classify and set colors independently so that this design often reflect the designer's subjective feelings but not the consumers. It leads to an adverse situation that detach from consumer. As a result, it creates a great deal of human, financial, and temporal waste. Therefore, it requires designers to deeply study the market trends and the psychological activities of most consumers. So, how to make the color design in the yacht can be combined with the consumer psychology is an important issue in the entire yacht sales process. The relationship between consumer psychology and color design includes emotional responses, cognitive feedback and behavioral responses. It is a necessary process for people to understand and respond to 
different things and is greatly applicable to relationships in transactions. Of course, most consumers typically have realistic psychology that means the selection of the color can not be too flashy. And we should choose the color according to yacht's function. For example, lively color for leisure and entertainment, sensitive security for navigatio and calm for business office. Comfortable and appropriate color design becomes the first factor in attracting consumers' desire to buy.

\section{B. The Influence of Color Design on Consumer Satisfaction}

Each color can give people different psychological and physical feelings. We can create a magical and unexpected visual effects by applicating this color effect in the yacht interior design. Such visual effects can affect buyer's satisfaction with the yacht. When buying yachts, consumers would consider many factors including the price, convenience, safety and aesthetics. What an excellent designer should do is to satisfy all the psychological needs of consumers as much as possible, and the color design determines such satisfaction in a certain extent. Colors are divided into warm and cold tone and different type may give consumers different feelings. The sense people received from the color is based on the experiences of real life. And it can not be evaluated by measuring physical temperature, which determines the designers need to have rich experience of life, for example the connection between the sun and red often bring people a warm feeling, and the connection between blue and sea always bring people a feeling of cold. Only the designers have a rich imagination can the psychology of consumer be catered. Different transparency also brings different feelings, in order to meet the different needs according to the functions, we have to use different color collocation. For example, for recreation yacht we can choose soft colors like pink, green and so on. For business using, we can choose a low transparency and high purity color, such as gray, black, which may bring people a sense of calm and trust. So the needs of consumers for targeted functions are satisfied, on the contrary, if the color does not match with the environment, it will greatly reduce consumer satisfaction and affect the feelings when using goods. Thus, the appropriate color design is important for the consumers satisfaction, the goods reputation and the development prospects.

\section{THE INTERIOR COLOR DESIGN IS IMPORTANT FOR THE PROMOTION AND MARKETING OF YACHT INDUSTRY}

With the improvement of people's material and spiritual pursuit, the development of yacht industry has rapidly developed in recent years. At the side of interior, designers must consider all aspects. The excellent interior color design can promote the development of the yacht industry, and it can more easily get a highly-praised word in marketing. The interior color design reflects the designer's feelings and conveys the feelings of the consumer. Under such human feelings, more people would be encouraged to pursue highquality life. In developed countries, people's material level has reached a certain level and the development of yacht industry is swift and violent. In recent years, China's yacht industry has developed quickly, which not only represents the Chinese people's material life level has improved, also represents the spirit of our state has been enhanced. Under such development, the yacht industry is known and accepted by more and more people and it has been promoted on a large scale.

\section{CONCLUSION}

With the improvement of the quality of life, people are demanding higher and higher color design. In the design of yacht, designers should learn to grasp the collocation of colors and the expression of color emotions, so as to cater for consumers' enjoyment. For designers, the accumulation of life experience and the scientific study of natural color are essential, and the application of color design in yacht interior may achieve a have great effect. Using color of imagination and creativity to express feelings and let consumers to fully understand the intention of the designer. Moreover, the value of the yacht can be exploited with the guidance of colors, so the color design can improve the competitiveness of yacht in the market. Good color design can satisfy the consumer's mind and guide people's consumption direction. Similarly, the psychological needs of consumers will gradually change with the alter of color design. Under such a trend, the influence of yacht interior color design on consumer psychology has become more and more fierce. People are also exploring the road of research and making great efforts to advance to high-quality life.

\section{REFERENCES}

[1] Zeng Junyuan. The design and application of recreational yacht styling based on Bionics [D]. Shaanxi University of Science and Technology, 2013.

[2] Zhang Lu. Yacht design guided by consumer psychology and consumer behavior [D]. Hunan University.

[3] Zhang Xin. Research on structural design and strength optimization of FRP Yacht[D]. Jiangsu University of Science and Technology

[4] Yang Lei. The research on computer aided design of FRP Yacht [D]. Huazhong University of Science and Technology, 2006.

[5] Guan Feifei. The reform research on "ship design" under the prospect of China independent design and independent construction of yacht [J]. technology, 2015, (07): 13+28.

[6] Cheng Juehao. The design and operation mode of yacht club [J] enterprise economy, 2006, (03): 26-28.

[7] Li Yawei. Research on style and function classification system of yacht [D]. Hunan University, 2011.

[8] Jiang Wengang, Shang Jie, Deng Zhiliang, Wang Dianming, Li Shaopeng. The research and design of high speed yacht driving simulation system $[\mathrm{J}]$. Journal of Jiangsu University of Science and Technology (NATURAL SCIENCE EDITION), 2005, (06): 12-15.

[9] Zhu Minhu. The selection and design of the yacht air conditioning equipment [J]. China ship science and technology, 2009, (01): 34-40.

[10] Handbook of design of high speed craft and yacht [J]. Chinese ship repair, 2010, (03): 49. 